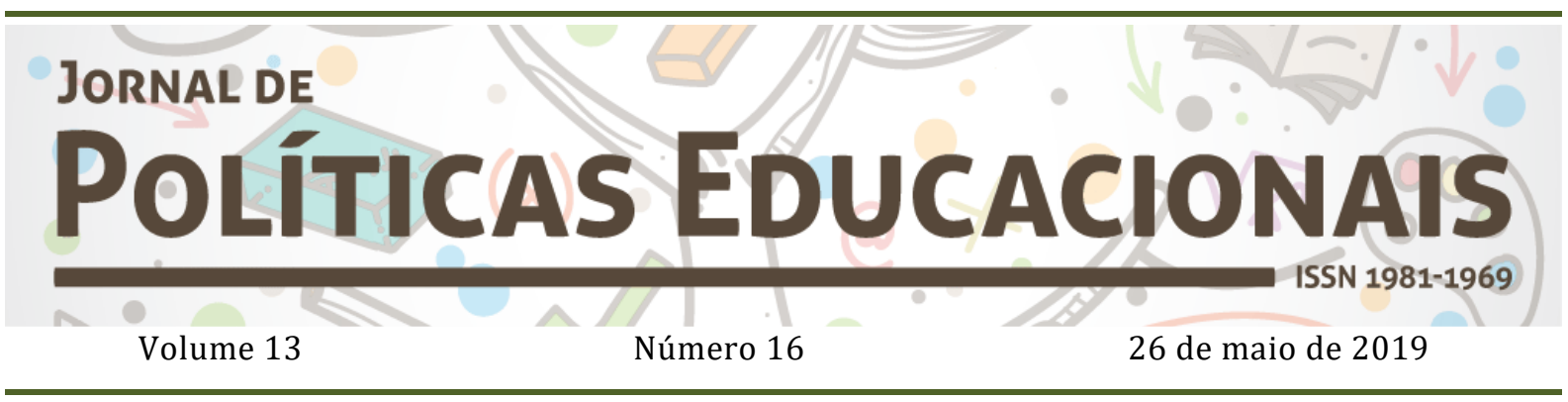

\title{
O grêmio estudantil e a gestão democrática: um estudo de caso no município de Messias-Alagoas
}

\author{
The student grain and democratic management: a case study in the \\ municipality of Messias-Alagoas
}

\section{El gremio estudiantil y la gestión democrática: un estudio de caso en el Municipio de Messias-Alagoas}

\author{
Alex Vieira da Silva \\ Vinícius André da Silva Santos ${ }^{2}$
}

Citação: SILVA, A. V. da; SANTOS, V. A. da S. O Grêmio Estudantil e a Gestão Democrática: um estudo de caso no Município de Messias-Alagoas. Jornal de Políticas Educacionais. V. 13, n. 16. Maio de 2019.

http:// 10.5380/jpe.v13i0.62082

\begin{abstract}
Resumo
O objetivo do texto é apresentar a concepção de gestores escolares e integrantes do grêmio estudantil sobre a sua importância e os trabalhos desenvolvidos na Escola Estadual Judith Nascimento da Silva, no município de Messias, estado de Alagoas. A metodologia utilizada pautou-se na abordagem qualitativa de cunho exploratória, sendo o estudo de caso o método de pesquisa. Foi utilizada a entrevista semiestruturada e participaram do processo o gestor, o vice-gestor e três integrantes que compõem o grêmio estudantil. Os resultados apontaram que a escola está em consonância com os dispositivos legais, uma vez que o grêmio estudantil atua de forma articulada com a direção da escola na tentativa da construção de uma gestão democrática e participativa. Porém, apresenta alguns limites e desafios na sua implementação, como: a) cativar o estudante para a prática da participação ativa; b) a corresponsabilidade nas atividades; e c) trabalhar a conscientização dos direitos e deveres dos estudantes, pois cada um é corresponsável pela organização da instituição educativa.
\end{abstract}

Palavras-chave: Gestão Democrática. Grêmio Estudantil. Participação.

\footnotetext{
${ }^{1}$ Mestre em Educação pelo Programa de Pós-graduação em Educação da Universidade Federal de Pernambuco (PPGE/UFPE).

${ }^{2}$ Graduando em Pedagogia, pela Universidade Federal de Alagoas - UFAL, membro do grupo de pesquisa Formação de Professores e Ensino de Ciências.
} 


\begin{abstract}
:
The purpose of this text is to present the conception of school managers and members of the student body about its importance and the works developed at the Judith Nascimento da Silva State School, in the municipality of Messias, state of Alagoas, Brazil. The methodology used was based on the qualitative approach of exploratory nature, the case study being the research method. The semi-structured interview was used and the manager, the deputy manager and three members of the student body participated in the process. The results pointed out that the school is in line with the legal provisions, since the student body acts in an articulated way with the direction of the school in the attempt of the construction of a democratic and participatory management. However, it presents some limits and challenges in its implementation, such as: a) captivating the student to practice active participation; b) co-responsibility in the activities; and c) work to raise awareness of the rights and duties of students, since each is responsible for the organization of the educational institution.
\end{abstract}

Key words: Democratic management. Student Guild . Participation.

\title{
Resumen
}

El objetivo del texto es presentar la concepción de gestores escolares e integrantes del gremio estudiantil sobre su importancia y los trabajos desarrollados en la Escuela Estadual Judith Nascimento da Silva, en el municipio de Messias, estado de Alagoas, Brasil. La metodología utilizada se basó en el abordaje cualitativo de cuño exploratorio, siendo el estudio de caso el método de investigación. Se utilizó la entrevista semiestructurada y participar en el proceso el gestor, el vice-gestor y 3 integrantes que componen el gremio estudiantil. Los resultados apuntaron que la escuela está en consonancia con los dispositivos legales, una vez que el gremio estudiantil actúa de forma articulada con la dirección de la escuela en el intento de la construcción de una gestión democrática y participativa. Sin embargo, presenta algunos límites y desafíos en su implementación, como: a) cautivar al estudiante para la práctica de la participación activa; b) la corresponsabilidad en las actividades; y c) trabajar la concientización de los derechos y deberes de los estudiantes, pues cada uno es corresponsable por la organización de la institución educativa.

Palabras clave: Gestión Democrática. Grêmio Estudiantil. Participación.

\section{Introdução}

A gestão democrática é um mecanismo significativo para a efetivação de um ensino público de boa qualidade (SILVA; SILVA; SANTOS, 2016). Para isso, faz-se necessário que a gestão da escola pública tenha os princípios da participação, da autonomia e da descentralização como instrumentos para a vivência de uma democracia que, de fato, envolva todos os segmentos escolares, bem como a comunidade a qual ela faz parte, possibilitando a participação ativa dos sujeitos nos processos decisórios da instituição educativa.

É importante que a organização escolar esteja pautada na participação da comunidade escolar e local, contribuindo na qualidade do processo de ensino e de aprendizagem e nas decisões de caráter administrativo e financeiro em busca de uma educação comprometida com a cidadania dos sujeitos. A participação envolve todos os funcionários da escola, pessoal técnico-administrativo, pessoal da limpeza, vigia, merendeiras, diretores, coordenadores, professores, estudantes, pais e responsáveis, bem como outras pessoas da comunidade interessadas no andamento da instituição educativa.

Contribuindo com essa discussão, Dalberio (2009, p.107) enfatiza: 
SILVA, A. V. da; SANTOS, V. A. da S. O grêmio estudantil e a gestão democrática: um estudo de caso no Município de Messias-Alagoas.

0 modelo de educação dentro de uma perspectiva democrática, antidiscriminatória, pela qual se vivencia uma gestão participativa, comprometida com a construção de uma escola pública popular de qualidade, busca formar alunos livres e conscientes e que conseguem fazer uma aproximação crítica entre a escola e a vida [...].

Como destaca Dalberio (2009), a gestão escolar na perspectiva democrática e participativa é aquela que está comprometida com a educação dos estudantes em uma visão emancipatória, visando à formação de sujeitos críticos e conscientes capazes de transformar a realidade na qual estão inseridos. A educação emancipatória está respaldada em uma educação voltada para a autonomia do sujeito, com perspectivas de um ensino crítico comprometido com a mudança social no qual o indivíduo se torna capaz de refletir sobre a realidade em que vive e busca transformá-la. Desse modo, essa concepção de educação e de gestão escolar defende que todos os segmentos estejam presentes no processo de elaboração da proposta pedagógica da escola a fim de organizar, planejar e refletir acerca da realidade na qual vivem e discutir sobre qual sujeito quer formar.

O texto tem como objetivo apresentar a concepção de gestores escolares e integrantes do grêmio estudantil sobre a sua importância e os trabalhos desenvolvidos na Escola Estadual Judith Nascimento da Silva, no município de Messias, estado de Alagoas. Nessa perspectiva, a vivência da democracia nos diferentes âmbitos da gestão escolar (administrativo, pedagógico e financeiro) é um artefato relevante para a conquista de práticas democráticas nas escolas públicas. De acordo com Dalberio (2008, p. 2), o contexto da democracia é como "um regime de governo no qual o poder de tomar importantes decisões políticas está com os cidadãos, que são os componentes da sociedade".

A pesquisa teve uma abordagem qualitativa de cunho exploratória, pois esse tipo de pesquisa tem como objetivo "conseguir informações e/ou conhecimentos acerca de um problema para o qual se procura uma resposta, ou de uma hipótese que se queira comprovar, ou, ainda, descobrir novos fenômenos ou as relações entre eles" (MARCONI; LAKATOS, 2015, p. 69).

No que se refere ao método de procedimento, foi utilizado estudo de caso. Este, por sua vez, foi significativo para o desenvolvimento da pesquisa, pois possibilitou aos pesquisadores terem contato direto com a escola para perceber a realidade, de modo a inferir e interpretar diferentes situações que são realizadas no cotidiano escolar (YIN, 2001). 
A técnica de coleta de dados foi a entrevista semiestruturada, participando do processo cinco integrantes, sendo eles o gestor, o vice-gestor e três estudantes que compõem o grêmio estudantil da Escola Estadual Judith Nascimento da Silva, no município de Messias, no estado de Alagoas. A análise de conteúdo na perspectiva de Bardin (2002) foi utilizada para analisar as concepções dos sujeitos sobre o grêmio estudantil.

O texto está estruturado em duas partes que se completam, além da introdução e das considerações finais. Na primeira parte são enfatizados os princípios e as referências que conduzem o grêmio estudantil no cenário da gestão democrática. Na segunda é apresentado um estudo de caso na realidade da uma escola estadual no município de Messias, no estado de Alagoas.

\section{O grêmio estudantil como mecanismo da gestão democrática: princípios e referências}

A participação se torna um aspecto propício na organização escolar, pois estabelece uma relação de diálogo permitindo a todos os envolvidos participar do funcionamento da escola, buscando uma prática educativa coerente para a realização de uma educação pública de boa qualidade. Assim, Libâneo (2012) destaca a importância de a comunidade escolar estar presente nos processos de tomada de decisão da escola, decidindo sobre qual rumo esta deve tomar para melhorar o seu funcionamento em busca de uma educação voltada para a aprendizagem dos estudantes e para a participação da comunidade em seu entorno.

A participação também possibilita a construção coletiva dos objetivos da escola em busca de um funcionamento democrático, por meio da discussão e do diálogo realizado por todos os envolvidos. Desse modo, a gestão democrática é um meio pelo qual as pessoas da comunidade escolar e local participam de suas ações no intuito de colaborar na prática educativa (SILVA; SILVA; SANTOS, 2016). Entretanto, essa colaboração não acontece pelo simples fato de estar na escola, participando das reuniões apenas para ouvir e acatar o que foi determinado pelo grupo gestor. Pelo contrário, a colaboração deve partir das discussões em que todos participam ouvindo, opinando e contribuindo para melhorar o funcionamento do ambiente escolar.

Nessa perspectiva, Souza $(2009$, p. 3) ressalta que: 
A gestão democrática é aqui compreendida, então, como um processo político no qual as pessoas que atuam na/sobre a escola identificam problemas, discutem, deliberam e planejam, encaminham, acompanham, controlam e avaliam o conjunto das ações voltadas ao desenvolvimento da própria escola na busca da solução daqueles problemas. Esse processo, sustentado no diálogo, na alteridade e no reconhecimento às especificidades técnicas das diversas funções presentes na escola, tem como base a participação efetiva de todos os segmentos da comunidade escolar, o respeito às normas coletivamente construídas para os processos de tomada de decisões e a garantia de amplo acesso às informações aos sujeitos da escola.

Compreende-se que a participação da comunidade local se torna possível quando a escola "abre as portas" para os sujeitos atuarem de forma significativa, na qual todos os segmentos - professores, estudantes, pais e funcionários - têm o poder de identificar os problemas, discutir sobre eles, analisá-los, acompanhar os processos da ação educativa, participando da construção dos objetivos almejados pela escola no que diz respeito à melhoria da educação, bem como os caminhos que norteiam uma prática democrática. A partir dessa análise, é necessário abrir espaço para o diálogo levando em consideração os sujeitos que se fazem presentes, suas especificidades, respeitando o que cada um apresenta para o funcionamento da escola (SOUZA, 2009).

Nessa perspectiva, a escola pode estabelecer um diálogo constante com todos os segmentos, na tentativa de descentralizar suas ações valorizando a participação e a formação de sujeitos autônomos. Essa autonomia deve prevalecer nas diferentes experiências da escola, de modo que busquem melhorar a instituição visando uma educação referenciada socialmente.

Para que se estabeleça a gestão democrática, é necessário que a escola vivencie as questões pertinentes a esse processo. A comunicação é um dos caminhos que perpassa pela gestão democrática, pois proporciona o engajamento dos segmentos no que diz respeito à melhoria da escola e, sobretudo, da educação. Quando a comunicação se faz presente entre os envolvidos, os rumos da escola são trilhados por caminhos necessários para a vivência de uma gestão escolar participativa.

No caso específico da consolidação da gestão democrática pelo segmento dos estudantes, o grêmio estudantil é o mecanismo no qual é referenciado para a participação desse público no processo de organização e de vivência coletiva.

O movimento estudantil teve surgimento no período da Idade Média na Europa, entre os séculos XIII e XIV (VALLE, 2008). Devido à baixa quantidade de universidades no ocidente e o número pequeno dos estudantes, as atividades realizadas não tinham a participação ativa desses sujeitos. Com a chegada do século XVI, os estudantes iniciam o 
SILVA, A. V. da; SANTOS, V. A. da S. O grêmio estudantil e a gestão democrática: um estudo de caso no Município de Messias-Alagoas.

processo de participação ativa de fatos históricos que levaram o fortalecimento da categoria, eclodindo distintas experiências e diferentes contextos, culturas e países. Dessa forma, a consolidação do movimento estudantil se deu pelas reivindicações políticas, econômicas e culturais. Nesse sentido, Valle (2008, p. 37) destaca que:

Em junho 1968, as manifestações estudantis tomam novamente as ruas, sendo vinculadas pelo governo às manifestações estudantis que eclodem em diversos países, a partir de maio, fortalecendo a divulgação de um plano internacional de subversão e da construção do inimigo externo.

As manifestações estudantis foram relevantes nessa época, pois combateram as atrocidades políticas e sociais, reivindicando e questionando as problemáticas educacionais e buscando melhorias para as dimensões sociais, culturais, políticas, econômicas e educacionais. As tensões e os embates foram oriundos da diferença de concepção de sociedade em que o governo e os estudantes tinham em suas ideologias. No Brasil, o movimento estudantil não difere dos outros países, a princípio as manifestações se concretizaram em cunho político no período da ditadura militar. Desde a luta da oposição ao regime militar (1964-1989); a favor da anistia (1979); “Diretas Já" (1984); "Fora Collor" (1993), ocupação das escolas do ensino médio (2016), entre outros, na busca de barrar a ideologia imposta pelo governo.

Com início do século XX, os grêmios estudantis são relacionados com o movimento estudantil, tendo os mesmos objetivos, mas agora especificamente educacional, conforme o estatuto do grêmio estudantil, que são: representar condignamente os discentes; defender os interesses individuais e coletivos do colégio; incentivar a cultura literária, artística e desportiva de seus membros; promover a cooperação entre administradores, funcionários, professores e alunos no trabalho escolar buscando seus aprimoramentos e lutar pela democracia permanente na escola, por meio do direito de participação nos fóruns internos de deliberação. Assim, caracteriza-se pela busca de direitos sociais a partir do poder instituído (HUR, 2009).

De acordo com Araújo (2009), os grêmios estudantis foram instituídos legalmente a partir das lutas pela democratização da educação no Brasil na década de 1980, consolidando-se na Lei no 7.398 , de 1985, a qual dispõe sobre a organização de entidades estudantis de $1^{\text {o }}$ e $2^{\text {o }}$ graus e assegura aos estudantes o direito dos jovens de se organizarem em grêmios. 
SILVA, A. V. da; SANTOS, V. A. da S. O grêmio estudantil e a gestão democrática: um estudo de caso no Município de Messias-Alagoas.

A Constituição Federal de 1988 também garante no artigo 206, inciso VI, a organização democrática do ensino público, possibilitando autonomia para as organizações e as instituições educativas a se organizarem de modo democrático, ou seja, garantindo a participação de todos na construção de um ensino de boa qualidade, mediante mecanismos que promovam o envolvimento dos sujeitos nas tomadas de decisões.

O Estatuto da Criança e do Adolescente (ECA) - Lei № 8.069, de 13 de julho de 1990 - mediante o artigo 53, inciso IV, garante o direito dos estudantes de se organizar e participar de entidades estudantis. Assim, como previsto no ECA, os estudantes têm a possibilidade, garantida por lei, de se organizar para a participação de movimentos estudantis, entres eles, o grêmio estudantil, no qual se constitui como um espaço educativo de socialização e de troca de experiências.

O Plano Nacional de Educação (PNE/2014-2024), na meta 19, apresenta as estratégias para a efetivação da gestão democrática e, especificamente, na estratégia 19.4 trata da implantação do grêmio estudantil nas escolas:

Estimular, em todas as redes de educação básica, a constituição e o fortalecimento de grêmios estudantis e associações de pais, assegurando-selhes, inclusive, espaços adequados e condições de funcionamento nas escolas e fomentando a sua articulação orgânica com os conselhos escolares, por meio das respectivas representações.

Em consonância com o PNE (2014-2024), o Plano Estadual de Educação de Alagoas (PEE/2015-2025) também apresenta na estratégia 19.4:

Apoiar e estimular, em todas as redes de educação básica, a constituição e o fortalecimento de grêmios estudantis e associações de pais e mestres, assegurando-lhes, inclusive, espaços adequados e condições de funcionamento nas escolas e fomentando a sua articulação orgânica com os conselhos escolares, por meio das respectivas representações.

Como determinam os planos de educação, o grêmio estudantil caracteriza-se como um instrumento de participação dos estudantes nas escolas da rede básica como garantia de uma gestão consolidada por meio do protagonismo juvenil. Assim, os alunos são vistos como "atores centrais desse processo, o alvo a ser atingido pela gestão democrática, pois a formação de alunos críticos, criativos e autônomos não vai ocorrer de forma espontânea, e deve ser estimulada e facilitada numa gestão democrática" (ARAÚJO, 2009, p. 258).

Para que haja entendimento dessa articulação de estudantes fazendo parte da organização dos processos educativos, cabe a gestão escolar ressignificar a formação 
SILVA, A. V. da; SANTOS, V. A. da S. O grêmio estudantil e a gestão democrática: um estudo de caso no Município de Messias-Alagoas.

desses sujeitos para além da educação formal, vivenciando uma aprendizagem cidadã que se constrói a partir do grêmio estudantil. Dialogando sobre a participação ativa, Martins e Dayrell (2013, p.1275) compreendem que:

O que nos parece importante é entendermos que tudo isso está ligado a um processo de ação educativa que pode proporcionar um rico aprendizado no lidar com o próximo, com outras pessoas de direitos, e, consequentemente, respeitar e reconhecer essas diferenças.

Nesse direcionamento da ação educativa do grêmio estudantil, o estudante percebe novos valores do ambiente educacional que lhe cabe por direito, em um exercício contínuo do protagonismo juvenil, expondo-se para as tomadas de decisões escolares, contribuindo para sua formação social. Com isso, "ele se forma nos mais variados espaços de convívio social e, com isso, apropria-se de experiências que, muitas vezes, eram cerceadas pela escola ou nem mesmo existiam em tal ambiente" (MARTINS; DAYRELL, 2013, p. 1271).

\section{A experiência do grêmio estudantil na rede estadual: o caso de Messias - Alagoas}

A proposta da implantação dos grêmios estudantis nas escolas está respaldada no PNE (2014-2024) e no PEE - AL (2015-2025), os quais determinaram a implantação do movimento estudantil nas escolas de todo o país. Assim, a Secretaria Estadual de Educação (SEDUC) de Alagoas promoveu encontros de formação para os gestores e os alunos no intuito de apresentar a importância dos grêmios estudantis para as escolas, efetivando um dos mecanismos da gestão democrática. O grêmio estudantil na Escola Estadual Judith Nascimento da Silva, município de Messias, Alagoas, foi reativado no ano de 2016 quando uma nova gestão assumiu a direção da escola e cumprindo uma determinação dos planos de educação estabelecidos.

Em relação à importância do grêmio, os gestores enfatizaram:

Auxiliar em algumas atividades pedagógicas, de tá verificando o que acontece na escola que é que tá faltando pra o aluno porque é como se fosse o porta-voz do aluno, da direção e da coordenação. A direção nem sempre tem esse olhar sobre todas as coisas que acontecem na escola e a gente sempre procura tá junto dessas pessoas (GESTOR).

É um apoio fundamental para a escola em várias questões, tanto questões pedagógicas, questões da organização da infraestrutura da escola, organização de biblioteca, dentre outros aspectos. Eles também são fundamentais na questão da conservação da estrutura da escola. A gente pede também esse apoio, essa colaboração. A escola passou por uma reforma há dois anos e meio e a gente para 
SILVA, A. V. da; SANTOS, V. A. da S. O grêmio estudantil e a gestão democrática: um estudo de caso no Município de Messias-Alagoas.

manter essa estrutura que é grande a gente conta também com o apoio do grêmio estudantil na questão educativa, de chamar o aluno, conversar com o aluno dizer a importância que é quanto manter a estrutura da escola bem conservada, o apoio deles com relação à escola (VICE-GESTOR).

Segundo o gestor, o grêmio estudantil é a voz dos estudantes, bem como auxilia na execução das atividades pedagógicas desenvolvidas na escola. 0 gestor atribui ao grêmio estudantil a responsabilidade de mediar as práticas vivenciadas pelos estudantes na escola no intuito de repassar as informações para a direção e coordenação. Desse modo, a fala do gestor situa-se na mesma perspectiva de Pavão e Carbello (2013, p. 3) quando apresentam que o grêmio estudantil "é a instância colegiada máxima de representação dos estudantes. Garante a participação estudantil na gestão escolar democrática, colaborando na luta para se alcançar o objetivo primordial da escola, a oferta de ensino de qualidade".

Na perspectiva das autoras, a função do grêmio estudantil não está voltada apenas para auxiliar as atividades de caráter pedagógico, uma vez que não impossibilita aos seus integrantes desenvolverem projetos, trabalhos relacionados ao exercício da prática pedagógica, mas sua função principal, enquanto mecanismo da gestão democrática, é contribuir para o ensino de boa qualidade por meio de reivindicações para a melhoria da instituição educativa, resistência às práticas autoritárias, defender seus direitos e interesses e incentivar e promover atividades educacionais, artísticas, culturais e sociais.

0 depoimento do vice-gestor também aponta para a compreensão do grêmio estudantil como um movimento de apoio à escola no que diz respeito às atividades de caráter pedagógico, administrativo e de organização da instituição. Ao mesmo tempo, a importância do grêmio estudantil, para ele, corrobora para o trabalho de conscientização aos demais estudantes da escola em relação à conservação e à preservação do espaço físico. 0 vice-gestor apresenta o grêmio quase como um órgão auxiliar ao trabalho dos gestores escolares. Percebe-se que não está em consonância com o que diz Libãneo (2004), pois aparenta uma tutela da gestão sobre as ações prioritárias do grêmio estudantil.

A visão apresentada pelos gestores em relação à importância do grêmio estudantil está pautada na colaboração dos integrantes para auxiliarem nos trabalhos da escola, na organização, na conservação e na preservação do ambiente escolar realizando o trabalho de conscientização ao corpo discente. Cabe sinalizar que, além dos aspectos apresentados, a participação ativa dos estudantes na organização da comunidade proporciona um 
SILVA, A. V. da; SANTOS, V. A. da S. O grêmio estudantil e a gestão democrática: um estudo de caso no Município de Messias-Alagoas.

aprendizado significativo para a construção da cidadania e de um sujeito crítico e reflexivo que poderá contribuir para a transformação da sociedade.

Diante desse contexto, outra estratégia utilizada pela escola para o envolvimento dos estudantes no processo da gestão democrática é o trabalho articulado entre o grêmio estudantil e o jornal escolar.

A gente tem também junto com o grêmio, a gente faz uma interlocução com o jornal da escola, onde a gente geralmente tenta unir as ações do jornal junto ao grêmio para que eles possam conversar entre si e desenvolver um bom trabalho com a questão da comunicação, do que anda acontecendo na escola, do que está para acontecer, como anda o andamento das atividades da escola (VICEGESTOR).

Essa estratégia da escola possibilita aos estudantes vivenciarem experiências democráticas de gestão, pois seus integrantes, tanto do grêmio estudantil quanto do jornal escolar, têm a autonomia de se organizarem para discutir as ações para o desenvolvimento das práticas educativas e sociais, como sinaliza Libâneo (2004, p. 131) “[...] é recomendável que tenham autonomia de organização e funcionamento, evitandose qualquer tutelamento por parte da Secretaria de Educação ou da direção da Escola".

A ação pedagógica e social do jornal escolar promovido pela escola em parceria com o grêmio estudantil possibilita uma intervenção na comunidade em que a escola está inserida, pois a partir da comunicação estabelecida por meio desse mecanismo de informação, as pessoas podem conhecer o trabalho da escola, as atividades realizadas, bem como os projetos futuros da instituição, o que torna a escola um espaço aberto de democratização das ideias coletivas.

Outro aspecto que cabe destacar é acerca das produções que o jornal escolar desenvolve fora da escola, levando comunicação, conhecimento e cobertura das questões políticas e sociais do município para diferentes dimensões. Acredita-se que a partir dessas vivências de interações, de troca de conhecimentos, da participação ativa no cotidiano escolar e na comunidade, "o indivíduo, ao atuar coletivamente, lida com suas tensões identitárias, constrói sua consciência e se reconhece dentro dos limites impostos pela sociedade e pelas relações sociais" (MARTINS; DAYRELL, 2013, p. 1272).

O depoimento de um integrante do grêmio estudantil revela a identidade desse movimento na escola:

A importância do grêmio pra escola é um grupo de alunos que sabe exatamente o que precisa, pelo fato de estar vivendo isso e pega ideias de toda escola em si para levar para coordenação, por que se for todo mundo não tem como eles 
acatar os pedidos dos alunos e o grêmio está aqui exatamente pra isso, pra ver o que precisa, o que a gente precisa, sentar junto com a coordenação pra tentar fazer melhoria pra gente e pra escola (ESTUDANTE A).

O estudante A apresenta que o grêmio estudantil é um espaço para que os estudantes possam discutir sobre as necessidades da escola e de seus usuários para o bom funcionamento da instituição, sempre havendo uma relação pacífica com a equipe gestora. Essa relação da equipe gestora com o grêmio estudantil pode garantir um trabalho coletivo e significativo para todos os envolvidos, uma vez que prioriza o diálogo, a compreensão e a tomada de decisões garantindo a participação de todos. Martins e Dayrell (2013) compreendem o grêmio estudantil como o local propício para estabelecer as relações pessoais e vivenciar práticas de companheirismo, de diálogo, de respeito às opiniões e posicionamentos do outro. Para as autoras, o grêmio é um espaço de aprendizagem para os que estão inseridos no movimento.

Em relação às atividades desenvolvidas pelos estudantes do grêmio estudantil da escola pesquisada, alguns projetos foram pensados para que pudessem contribuir com o funcionamento da escola.

A princípio a gente vai deixar a biblioteca com a cara mais dos alunos, para que fique mais atraente para que eles possam usar, porque tem funcionários, mas não é o suficiente para ficar aqui supervisionando a entrada e saída de livros e a gente tá pensando em reabrir a biblioteca, tem alguns que gosta de ler na hora de intervalo, é melhor ler do que tá bagunçando (ESTUDANTE A) (grifos nossos).

Abrir o laboratório de informática que precisa fazer uma pesquisa, o laboratório de informática já tá à disposição porque a gente tem, só não está funcionando. Aí esse é um projeto do grêmio, para abrir o laboratório de informática e a biblioteca para melhoria do desenvolvimento dos alunos (ESTUDANTE B) (grifos nossos).

A gente já tem um projeto, que a gente está praticamente criando uma creche para os alunos da noite que tem filhos. Aí algumas pessoas vêm se revezando para cuidar dos filhos dos alunos, enquanto eles tão assistindo a aula a gente tá cuidando deles, pra não atrapalhar tanto a aula. Através disso aí traz mais ensino para os pais né, porque os pais prestam mais atenção na aula do que do filho. E os professores conseguem desenvolver sua aula sem interrupções (ESTUDANTE C) (grifos nossos).

Os projetos descritos caracterizam-se como relevantes para o exercício da participação dos estudantes na organização política da escola, uma vez que os integrantes do grêmio estudantil elaboraram os projetos mediante as necessidades percebidas por eles na instituição e em conversa com os demais estudantes. Reabrir a biblioteca da escola e colocar em funcionamento o laboratório de informática possibilita aos estudantes terem 
acesso a esses meios de comunicação e de informação, entendidos como mecanismos necessários para o desenvolvimento da aprendizagem (LIBÂNEO, 2004).

Pode-se perceber nos depoimentos dos estudantes que os projetos pensados por eles tendem a ocupar os espaços ociosos da escola, fazendo com que sejam aproveitados por todos os que estão inseridos na instituição, mesmo que para isso eles se submetam a assumir as responsabilidades que seriam de um funcionário contratado pelo Estado.

Outro aspecto a destacar é a proposta sinalizada pelo estudante $\mathrm{C}$ quando relata que "a gente está praticamente criando uma creche para os alunos da noite que têm filhos". No entanto, essa proposta parece descaracterizar a função do grêmio estudantil como porta voz dos estudantes e canal do protagonismo juvenil, pois responsabiliza o grêmio de atender uma demanda que compete ao Estado. Mesmo sendo necessária a organização de uma política diferenciada da escola para atender aos alunos do noturno, geralmente pessoas com filhos, não é de responsabilidade do grêmio estudantil assumir essa função. Cabe à escola pensar outra estratégia para tentar solucionar essa problemática, uma vez que a presença das crianças na sala de aula pode atrapalhar a condução das atividades.

De um modo geral, o movimento dos estudantes de estar presente cuidando da escola, preocupando-se para atender as demandas, fazendo um trabalho de cooperação juntamente com a gestão pode contribuir como uma experiência significativa na vida deles, pois o envolvimento dos estudantes nesse meio garante o desenvolvimento de uma consciência crítica e reflexiva, de modo que possam atuar na sociedade desenvolvendo práticas democráticas e assumindo compromissos e responsabilidades inerentes ao cidadão.

A relação entre o grêmio estudantil e a gestão da escola é uma importante ação para a resolução dos problemas da instituição, como destaca o gestor "a escola não é da gente, a escola é deles. Então eles que tem que tá na ativa também". Assim, "o grêmio estudantil não é instrumento de luta contra a direção da escola, mas uma organização onde se cultiva o interesse dos estudantes, onde eles têm possibilidade de democratizar decisões e formar o sentimento de responsabilidade" (VEIGA, 2007, p. 123). Manter um diálogo e atuar ativamente nas tomadas de decisões é um aspecto necessário para desenvolver um trabalho interativo com compromisso, responsabilidade e respeito por cada segmento. 


\section{Considerações Finais}

O grêmio estudantil é um canal de participação da gestão democrática que possibilita aos estudantes um envolvimento na escola no intuito de contribuir para o andamento da instituição educativa que, por sua vez, garante a autonomia, a representatividade e a atuação ativa e interventora nos direcionamentos da escola, tornando-se um instrumento relevante para o exercício da cidadania, da democracia, da participação e do protagonismo dos estudantes na dimensão política do "chão" da escola, possibilitando a discussão, a deliberação, a tomada de decisões e a possibilidade de intervir na sociedade.

No contexto das relações de decisões educativas, pode-se apresentar que há divergências e convergências, as quais são resultados das correlações de forças presentes nos espaços sociais, no caso em análise, a escola pública. Dessa forma, os conflitos podem estar presentes nas propostas vivenciadas pela escola e seus diferentes grupos e movimentos, caracterizando possíveis embates nas experiências desencadeadas no espaço coletivo. No caso da escola em questão, não foi possível perceber essas relações uma vez que os participantes não externaram em suas vozes tensões no processo de organização do grêmio estudantil.

A realidade da escola pesquisada apresenta-se em consonância com os dispositivos legais, uma vez que o grêmio estudantil atua de forma articulada com a direção da escola na tentativa da construção de uma gestão democrática e participativa. Porém, o movimento estudantil apresenta alguns limites para a sua efetivação e implementação, como destacou o gestor, "o maior desafio ainda é você cativar o aluno e mostrar que aquilo que ele tá fazendo não é em prol da direção, não é em prol da coordenação, nem do professor, é em prol do próprio aluno".

Cabe sinalizar que na realidade em questão, a autonomia do grêmio estudantil é limitada, pois as práticas vivenciadas pelos estudantes são oriundas a partir das proposições apresentadas pela gestão escolar, descaracterizando a autonomia do grupo de estudantes nas atividades inerentes ao movimento estudantil. Dessa forma, pode-se compreender que a gestão democrática requer ações dos diferentes segmentos na perspectiva de que todos sejam partícipes, tenham autonomia e não estejam centrados exclusivamente no tutelamento dos gestores. 
Nessa perspectiva, o grêmio estudantil da escola estadual do município de Messias, no estado de Alagoas, ainda requer maior envolvimento dos estudantes de modo que eles planejem suas ações por meio das atividades que lhes são inerentes, destacando-se a construção coletiva do regimento do grêmio estudantil, a elaboração de projetos com os demais estudantes da escola, propostas que movimentem as práticas escolares na tentativa de rompimento das ações autoritárias dos profissionais, entre outras.

Como resultado da pesquisa, ficou nítido no depoimento do gestor que os estudantes ainda carecem de maior participação e conscientização das práticas que os envolvem para a melhoria da educação. Nas palavras do gestor, "o aluno só participa de alguma atividade se receber alguma coisa em troca, por exemplo, quando a gente diz 'vamos fazer alguma coisa na sala de aula'; 'mas ganha ponto?'. Infelizmente, a gente ainda tem esse padrão que aos poucos a gente tem que ir quebrando. 'vamos participar de um desfile cívico'; 'vai ganhar ponto?'”.

Nesse cenário, o papel da escola e dos seus profissionais é possibilitar ações que evidenciem a participação dos estudantes, a fim de despertar o interesse pelas práticas que envolvem decisões, ações, projetos e questões pertinentes aos próprios estudantes. 0 protagonismo estudantil é configurado pelas propostas designadas por todos os participantes, tendo como epicentro do projeto educativo os ideais e os anseios do coletivo.

Diante do contexto, destaca-se a importância da gestão escolar, bem como dos profissionais da educação reconhecerem a legitimidade dos grêmios estudantis como entidades representativas que atendem as necessidades dos estudantes. No entanto, a autonomia estudantil deve prevalecer, oportunizando espaços para que as vozes e as propostas dos estudantes sejam respeitadas e viabilizadas no dia a dia da escola.

\section{Referências}

ARAÚJO, Adilson Cesar de. A gestão democrática e os canais de participação dos estudantes. Revista Retratos da Escola, Brasília, v. 3, n. 4, p. 253-266, jan./jun. 2009.

BARDIN, Laurence. Análise de conteúdo. Trad. Luís Antero Reto e Augusto Pinheiro. Lisboa: Edições 70, 2002.

BOUTIN, Aldimara Catarina Brito Delabona; FLACH, Simone Fatima. Emancipação humana, emancipação política e grêmio estudantil: alguns apontamentos. ECS, Sinop/MT/Brasil, v. 5 n. 2, p. 136-147, jul/dez. 2015. 
BRASIL. Constituição da República Federativa do Brasil. Brasília, 1988.

BRASIL. Lei no 8.069/90 - Estatuto da Criança e do Adolescente, Brasília, 1990.

BRASIL. Presidência da República. Lei n 13.005. Aprova o Plano Nacional de

Educação e dá outras providências. Brasília, 25 de junho de 2014.

DALBERIO, Maria Célia Borges. Gestão democrática e participação na escola pública popular. Revista Iberoamericana de Educación. № 47/3 - 25 de outubro de 2008.

DALBERIO, Maria Célia Borges. Neoliberalismo, políticas educacionais e a gestão democrática na escola pública de qualidade. São Paulo: Paulus, 2009.

ESTADO DE ALAGOAS. Plano Estadual de Educação 2015-2025. Secretaria Estadual de Educação.

HUR, Domenico Uhng. Discursos do trânsito da guerrilha ao Estado neoliberal: estratopolítica, tecnopolítica e nomadopolítica. Tese (Doutorado em Educação) Instituto de Psicologia da Universidade de São Paulo, 2009.

LAKATOS, Eva Maria; MARCONI, Marina de Andrade. Técnicas de pesquisa: planejamento e execução de pesquisas, amostragens e técnicas de pesquisa, elaboração, análise e interpretação de dados. São Paulo: Atlas, 2015.

LIBÂNEO, José Carlos. Organização e Gestão da Escola: teoria e prática. 5. ed. Goiânia: Alternativa, 2004.

LIBÂNEO, José Carlos; OLIVEIRA, João Ferreira; TOSCHI, Mirza Seabra. Educação escolar: políticas, estrutura e organização. São Paulo: Cortez, 2012.

MARTINS, Francisco André Silva. DAYRELL, Juarez Tarcísio. Juventude e Participação: o grêmio estudantil como espaço educativo. Educação \& Realidade, Porto Alegre, v. 38, n. 4, p. 1267-1282, out./dez. 2013.

PAVÃO, Gislaine Cristina. CARBELLO, Sandra Regina Cassol. Grêmio estudantil: uma instância colegiada em debate. XI Congresso Nacional de Educação EDUCERE, 2013.

SILVA, Givanildo da. SILVA, Alex Vieira da. SANTOS, Inalda Maria dos. Concepções de gestão escolar pós-LDB: o gerencialismo e a gestão democrática. Revista Retratos da Escola. v. 10, n. 19, jul./dez. 2016.

SOUZA, Ângelo Ricardo de. Explorando e construindo um conceito de gestão escolar democrática. Educação em Revista. V. 25 - no 03, Belo Horizonte, 2009.

VALLE, Maria Ribeiro do. As representações da violência nos episódios estudantis de 1968. Mediações. v. 13, n.1-2, p. 34-53, Jan/Jun e Jul/Dez. 2008.

VEIGA, Zilah de Passos Alencastro. As Instâncias Colegiadas da Escola. In: VEIGA, Ilma 
SILVA, A. V. da; SANTOS, V. A. da S. O grêmio estudantil e a gestão democrática: um estudo de caso no Município de Messias-Alagoas.

Passos Alencastro; RESENDE, Lúcia Maria Gonçalves de. (Orgs.). Escola: espaço do projeto político-pedagógico. 11. ed. Campinas: Papirus, 2007 (p. 113-126).

YIN, Roberto K. Estudo de caso: planejamento e método. Porto Alegre : Bookman, 2001. 


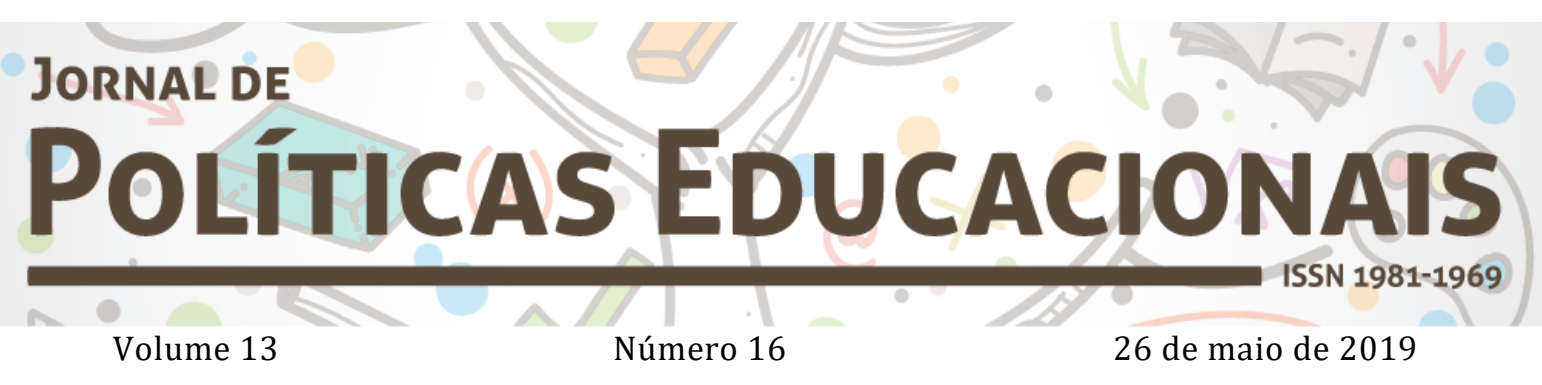

\begin{abstract}
(C)
SORAERIGHIS RESERVED O Copyright é retido pelo/a autor/a (ou primeiro co-autor) que outorga o direito da primeira publicação ao Jornal de Políticas Educacionais. Mais informação da licença de CreativeCommons encontram-se em http://creativecommons.org/licenses/by-nc-nd/2.5. Qualquer outro uso deve ser aprovado em conjunto pelo/s autor/es e pelo periódico.

JoRnAL DE Políticas EdUCACIONAIS é uma publicação do Núcleo de PolíticasEducacionaisdo Setor de Educação da Universidade Federal do Paraná - NuPE/UFPR, em consórcio com a Linha de Pesquisa em Políticas Educacionais do Programa de Pós-Graduação em Educação - PPGE/UFPR, que aceita colaboração, reservando-se o direito de publicar ou não o material espontaneamente enviado à redação. As colaborações devem ser enviadas ao NuPE/UFPR, conforme orientações contidas nas páginas do periódico na internet: http://revistas.ufpr.br/jpe.
\end{abstract}

\author{
Indexação: \\ BBE - Biblioteca Brasileira de Educação (MEC/INEP) \\ Clase (Base de Datos Bibliográfica de Revistas de Ciencias Sociales y Humanidades) \\ Diadorim - Diretório de Política de Acesso Aberto das Revistas Científicas Brasileiras (IBICT) \\ Google Scholar \\ Index Copernicus \\ Portal de Periódicos (CAPES) \\ SER - Sistema Eletrônico de Revistas da Universidade Federal do Paraná (SER/UFPR) \\ Sumários de Revistas Brasileiras (FUNPEC-RP) \\ DRJI - Directory of Research Journals Indexing
}

(Periódico integralmente disponível apenas em via eletrônica)

Jornal de Políticas Educacionais / Núcleo de Políticas Educacionais da Universidade Federal do Paraná NuPE/UFPR - v.1, n. 1 (1ํs semestre de 2007) - Curitiba: NuPE/UFPR.

Volume 13, número 16 - Maio de 2019

ISSN 1981-1969

1. Educação - Periódicos. 2. Política Educacional - Periódicos. I. NuPE/UFPR

Comitê Editorial:

Elisângela Scaff (UFPR)

Daniela de Oliveira Pires (UFPR)

Ana Lorena Bruel (UFPR)

Conselho Editorial:

Andréa Barbosa Gouveia (UFPR), Ângela Hidalgo (UNICENTRO), Cesar GernominoTello (Universidad Nacional TresFebrero, Argentina),Gladys Beatriz Barreyro (USP), Juca Gil (UFRGS), Jefferson Mainardes (UEPG), João Ferreira de Oliveira (UFG), Luiz Souza Júnior (UFPB), Marcos Edgard Bassi (UFSC), Regina 
SILVA, A. V. da; SANTOS, V. A. da S. O grêmio estudantil e a gestão democrática: um estudo de caso no Município de Messias-Alagoas.

Maria Michelotto (UFPR), Robert Verhine (UFBA), Rosana Cruz (UFPI), Rubens Barbosa Camargo (USP), Sebastián Donoso Díaz (Universidad de Talca, Chile), Taís Moura Tavares (UFPR), TheresaAdrião (UNICAMP), Vera Peroni (UFRGS).

Créditos e Agradecimentos:

Revisão de Língua Portuguesa, Abstract e Resumen: PROGRAMA DE APOIO ÀS PUBLICAÇÕES CIENTÍFICAS PERIÓDICAS DA UFPR

Arte e diagramação: TIAGO TAVARES (iagotav@gmail.com)

Jornal de Políticas Educacionais

Universidade Federal do Paraná

Setor de Educação

Núcleo de Políticas Educacionais - NuPE/UFPR

Avenida Sete de Setembro, 2645

$2^{\circ}$ andar, Sala 213

80.230-010 - Curitiba - PR - Brasil

Tel.: 41-3535-6264

jpe@ufpr.br

http://revistas.ufpr.br/jpe 